\section{Temperament Does Not Affect Steer Weight Gains on Extensively Managed Semiarid Rangeland}

\author{
By Justin L. Reeves, and Justin D. Derner
}

\section{On the Ground}

- Cattle with poor temperaments gain less weight in feedlots. However, how yearling steer temperament affects weight gain on rangelands is a knowledge gap for ranchers.

- Flight speed, the speed at which cattle exit a chute after weighing, has been used to measure temperament in past feedlot studies (faster speed $=$ poor temperament). We used flight speed scores in this study to measure yearling steer temperament at the beginning (mid-May) and end (early-October) of grazing seasons for 3 years: 2011-2013.

- We hypothesized that steer weight gains on extensively managed semiarid rangeland with low stocking densities ( 0.11-0.15 steers/ha) would not be influenced by temperament due to the much lower animal densities and fewer handling events than experienced in feedlots.

- No meaningful relationships were found between season-beginning or season-ending flight speed score and steer average daily gain, and flight speed scores were often lower at the end of the season.

- Results suggest that ranchers operating stocker enterprises with extensive management and low stocking densities on rangelands can potentially be less selective for temperament when assembling herds.

Keywords: cattle, flight speed, behavior, shortgrass steppe.

Rangelands 37(5):186-190

doi 10.1016/j.rala.2015.07.004

(C) 2015 The Society for Range Management

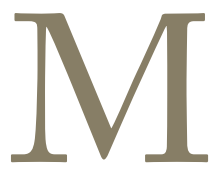

ost ranchers have first-hand experience with differences in cattle temperament, from the cow that will blow her top when her calf is taken to be tagged, to the herd pet that needs a good scratch behind the ears before anything else can be done with the rest of the herd. Everyone likes their docile animals, as cattle with poor temperaments are not much fun to work and can even be dangerous to handlers. Beyond this added danger, cattle with poor temperaments can also have tougher meat ${ }^{1,2}$ and reduced weight gains ${ }^{2-4}$ in feedlots. As one example, cattle with poor temperaments gained $0.19 \mathrm{~kg} / \mathrm{hd} /$ day (or $0.42 \mathrm{lb} / \mathrm{hd} /$ day) less than their counterparts with calm temperaments. ${ }^{3}$ Temperament can clearly be an important consideration when assembling herds, not only from a safety standpoint ${ }^{5}$ but also from an economic standpoint, ${ }^{6}$ as lower weight gains and tougher meat would clearly affect bottom lines. Multiple factors, such as cattle breed, ${ }^{3,7,8}$ genetics, ${ }^{8,9}$ gender, and background, ${ }^{8}$ can influence cattle temperament, so understanding such influences (and especially their relationship to beef production and quality) would clearly be valuable to ranchers.

To help make wise breeding and herd assembly decisions regarding temperament, the American Angus Association (www.angus.org) has maintained a docility Expected Progeny Difference (EPD) since spring 2008.6 Although such resources exist and the effects of temperament on cattle performance in feedlots are well known, how yearling steer temperament affects weight gain on rangelands remains a knowledge gap for ranchers. On European pastures, less docile calves have been shown to have reduced weight gains, ${ }^{8}$ but it still remains possible that when grazing extensively managed rangelands, the relationship between temperament and weight gains may differ from feedlots.

To test the relationship between temperament and yearling steer weight gains on semiarid rangeland, cattle chute-exit behavior was evaluated for 3 years (2011-2013) at the United States Department of Agriculture - Agricultural Research Service, Central Plains Experimental Range near Nunn, Colorado. Cattle "flight speed" or "exit speed" is one widely used method to study cattle temperament ${ }^{8,10-12}$ and is simply the speed at which an animal exits a chute after handling (faster speed = poor temperament). For this study, we assigned flight speed scores ${ }^{8,12}$ during weighing events of yearling steers. These data were used to test the hypothesis that steer 
Table 1. Yearly data (independent of flight speed scores) for spring (April-June) precipitation and corresponding forage production (estimated from a representative study pasture), mean steer season-beginning weight, and mean steer average daily gain (ADG) at the Central Plains Experimental Range.

\begin{tabular}{|l|l|l|l|l|}
\hline Year & Spring precipitation $(\mathbf{m m})$ & $\begin{array}{l}\text { Forage production } \\
\mathbf{( k g / h a )}\end{array}$ & $\begin{array}{l}\text { Mean steer } \\
\text { season-beginning } \\
\text { weight (kg } \pm \mathbf{S D})\end{array}$ & $\begin{array}{l}\text { Mean steer ADG } \\
\mathbf{( k g / h d / d a y ~} \pm \text { SD) }\end{array}$ \\
\hline 2011 & 164 & 814 & $271.4 \pm 25.0$ & $1.04 \pm 0.16$ \\
\hline 2012 & 40 & 336 & $294.5 \pm 29.1$ & $0.75 \pm 0.14$ \\
\hline 2013 & 119 & 730 & $277.7 \pm 24.5$ & $0.87 \pm 0.14$ \\
\hline
\end{tabular}

weight gains on extensively managed semiarid rangeland would not be influenced by temperament due to the much lower animal densities and fewer handling events than experienced in feedlots. Determining if a relationship exists (or not) between steer temperament and weight gains on rangelands would help ranchers make more informed herd assembly decisions for stocker operations, which was one of the primary goals of this study.

\section{Study Location, Facilities, and Methods}

The Central Plains Experimental Range (CPER) is located about $12 \mathrm{~km}$ northeast of Nunn, in north-central Colorado. Mean annual precipitation is $341 \mathrm{~mm}$; mean growing season (April-September) precipitation is $274 \mathrm{~mm}$. The cattle handling facilities at CPER were designed and constructed by Grandin Livestock Handling Systems, Inc., Fort Collins, Colorado in 2003, following low-stress facilities principles. ${ }^{13,14}$ For instance, the facility has a high-fenced, cornerless alley with a nonslip floor, and all handlers are trained to remain quiet and calm and to utilize "flight zone" and "point of balance" principles to move only small groups of steers through the facility at a time. ${ }^{15}$ For season-beginning (mid-May) and season-ending (early- October) weighing events that were performed as a regular part of other grazing experiments, steers were gathered beginning at 3:00 p.m. the day prior to weighing and gathering was completed within 1 hour. Steers were then held overnight without feed or water in a corral that gave each animal four times the industry standard of $\sim 1.9 \mathrm{~m}^{2}$ per animal. ${ }^{13}$ Steers were individually weighed beginning at 8:00 AM the next day. To weigh steers and determine steer temperament, a Heavy Duty Extended Model Silencer hydraulic squeeze chute with a platform scale was used. At all stages of the gathering and weighing processes, cattle handlers used low stress cattle handling techniques. ${ }^{15}$ All experimental protocols were approved by the CPER Animal Care and Use Committee.

\section{Grazing Experiment and Flight Speed Scoring}

All steers across study years $(2011-2013 ; \mathrm{n}=1638)$ were Bos taurus and privately owned by ranchers in the Crow Valley Livestock Cooperative, Inc. New sets of steers from various producers were used each year. Steer color was recorded by the investigators each year for identification purposes, but color was not reliably equated to breed (breed information was not provided by ranchers). Study steers were all yearlings born the prior spring and the majority $(\sim 2 / 3)$ were black colored. Low stocking densities of $\sim 0.15$ steers/ha (0.06 steers/acre) were used in 2011 and 2012; this was reduced to $~ 0.11$ steers/ha (0.045 steers/acre) in 2013 due to severe drought in 2012 (Table 1). For each year, steers were randomly placed in pastures that were either 65 or 130 ha at a moderate stocking rate of $~ 0.6$ animal unit months per hectare (AUM/ha). Steers were continuously grazed for the entire grazing season (mid-May to early- October) and were weighed at the beginning and end of each grazing season to assess weight gains as a regular part of other grazing experiments. During the season-beginning weighing, steers were given a pour-on insecticide and an ear tag. Throughout the grazing season, steers were counted and visually examined for health issues at a distance from vehicles three times per week with minimal handling otherwise. Distances from study pastures to county roads, which bisect CPER, were similar and all pastures contained two-track trails around pasture perimeters.

Similar to prior studies, we used cattle flight speed scores as a measure of temperament. ${ }^{8,11,12}$ The scores used were: 1 = walk; 2 = trot; $3=$ run; $4=$ jump. ${ }^{8}$ These scores represented the speed at which the steers exited the chute and were assigned immediately after steer weight was recorded and the chute gate was opened. Steers were in the chute for less than 20 seconds on average. For all measurements, the observers were behind the chute opening, and no humans were in front of or directly beside the steers during chute release or scoring. When steers rarely fell out of the chute upon release at either the beginning or end of the season, these animals were excluded from the dataset $(\mathrm{n}=24$ total steers across years) because it was impossible to determine if agitation (or other factors, such as accidental loss of balance) caused the fall. This rating system was selected because it was easy to use and equipment was not available to measure actual flight speed. ${ }^{10}$ However, the methods used here have been shown to be closely related to (and interchangeable with) actual flight speed, making them useful for determining temperament relationships to weight gain. ${ }^{8,12}$ For all 3 study years, two observers (same two each year) assigned flight speed scores. Scores were immediately 

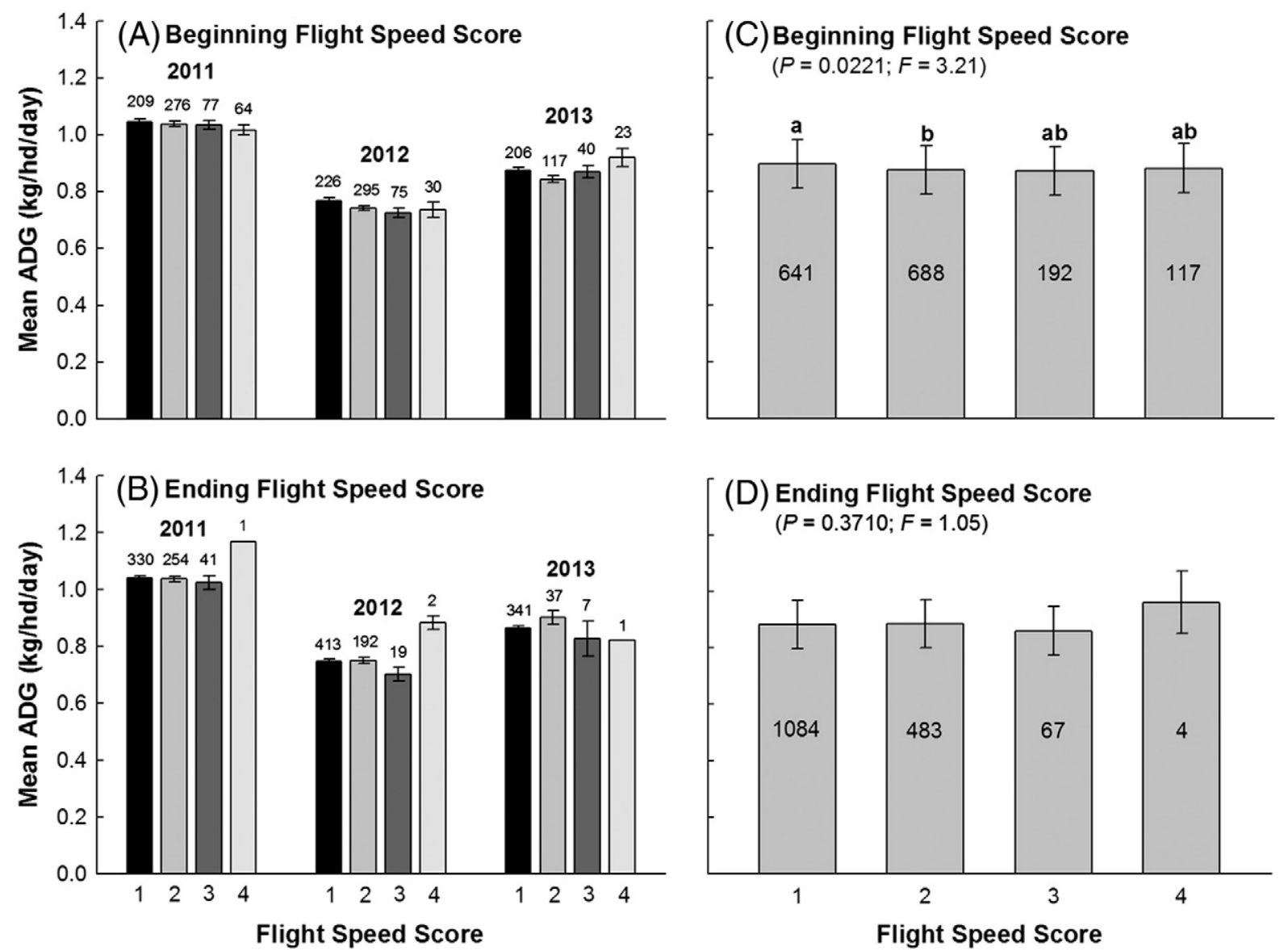

Figure 1. Mean steer average daily gain (ADG; kg/hd/day; \pm SE) for each study year (2011-2013) by season-beginning (panel $A$ ) and season-ending (panel B) flight speed score $(1=$ walk; $2=\operatorname{trot;} 3=$ run; $4=$ jump). Numbers above bars in panels $A$ and $B$ are number of steers at that score. Panels $C$ (season-beginning) and D (season-ending) represent steer ADG by flight speed score according to the statistical model (least squares means \pm SE). The model accounted for year and pasture difference effects on steer weight gains, so panels $C$ and D show pure effect of temperament on ADG. The letters above the bars in panel $\mathrm{C}$ are results from the Tukey HSD tests; different letters indicate statistically significant differences between scores. Values within bars for panels $C$ and $D$ represent number of steers at that score.

discussed and agreed upon for each steer in rare cases (estimated $<5 \%$ ) of initial disagreement.

To test for relationships between flight speed score and average daily gain over the grazing season (ADG; $\mathrm{kg} / \mathrm{hd} /$ day), we used a mixed statistical model (REML method) in the statistical analysis program JMP 10.0.0 (SAS Institute Inc., Cary, NC). The model included year and pasture as random effects to account for differences in steer groups and forage production (see Table 1) across years, as well as differences in steer weight gain by pasture (that would have been unrelated to flight speed/temperament). Both season-beginning and season-ending flight speed scores were tested separately as fixed effects for relationships with weight gain.

\section{Steer Weight Gain Not Related to Temperament}

Independent of temperament, steer weight gains differed by year at CPER due to variations in precipitation and corresponding forage production (see Table 1; Fig. 1A and B). However, our statistical model took these differences into account. Although the model found a statistically significant effect of season-beginning flight speed score on weight gain between steers with scores of 1 and 2 (Fig. 1C), the difference was very small $(\sim 0.02 \mathrm{~kg} / \mathrm{hd} /$ day more for $1 \mathrm{~s}$ than $2 \mathrm{~s})$. The difference was likely only found by the model because of high numbers of steers in the dataset (i.e., high statistical power; $\mathrm{n}=$ 641 and 688 steers with scores of 1 and 2, respectively). All other comparisons between other season-beginning scores were non-significant (see Fig. 1C) and there was no effect of season-ending flight speed score on steer ADG (Fig. 1D).

Across years, to start the grazing season, steers were most likely (42\%) to display a flight speed score 2 (trot; see Fig. 2A). However, to end the grazing season, steers were most likely (66.2\%) to exhibit a score of 1 (walk; see Fig. 2A). Scores of 3 (run) and 4 (jump) represented $11.7 \%$ and $7.1 \%$ of total steers across years, respectively, to start the grazing season. At season's end, these percentages dropped to just $4.1 \%$ and $0.2 \%$, respectively (see Fig. 2A). Mean seasonal flight speed score difference (start minus end score) across all steers ( $\mathrm{n}=$ 1638) was $-0.5 \pm 0.8 \mathrm{SD}$. Mean score difference was $-1.0 \pm$ $0.9 \mathrm{SD}$ across steers that changed in flight speed score at the end of the season (i.e., non-zero difference; $\mathrm{n}=772$ ). 

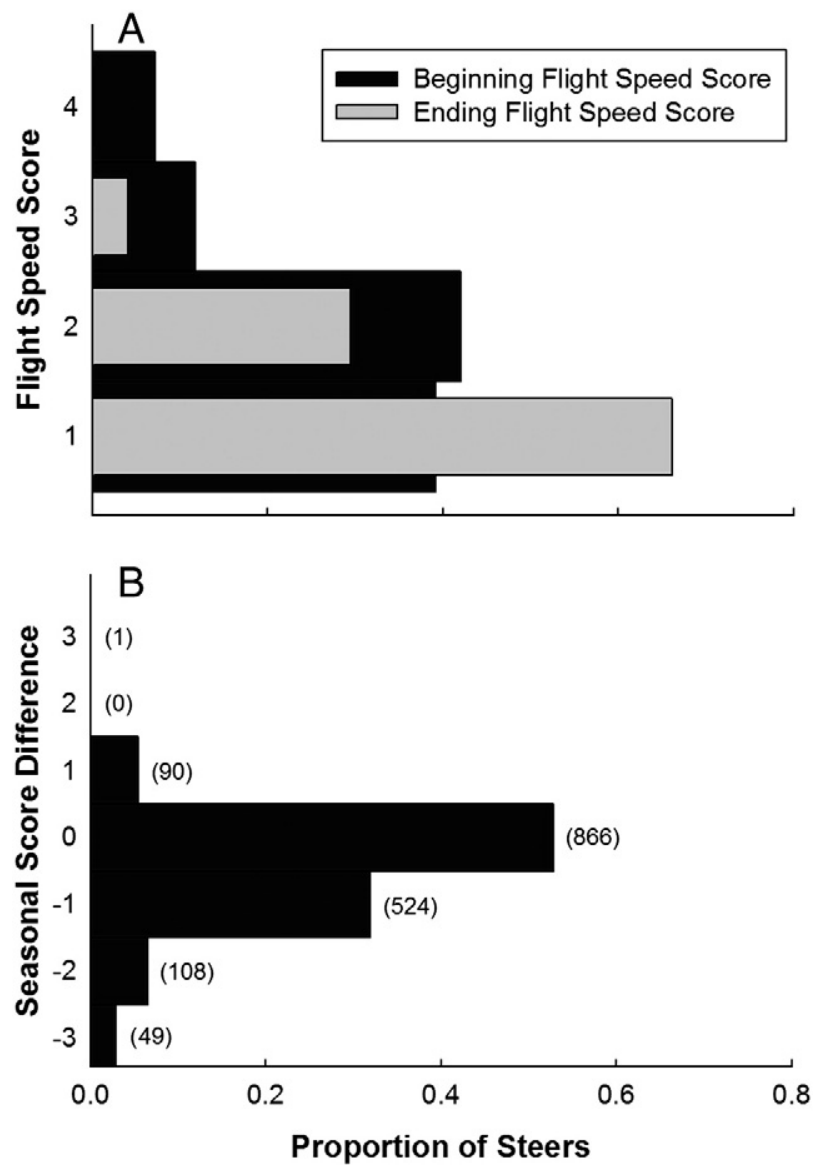

Figure 2. Flight speed score distributions across years (2011-2013). Panel A shows the proportion of steers at each flight speed score $(1=$ walk; $2=$ trot; $3=$ run; $4=$ jump) for the beginning (dark bars) and end (light bars) of the grazing season (numbers of steers at each flight speed score are presented in Fig. 1). Panel B shows distribution of differences in flight speed scores between the beginning and end of the grazing season (season-ending score minus season-beginning score). Negative values indicate steers which were calmer during weighing at the end of the grazing season; positive values indicate steers which were more agitated. Values for bars in panel B represent total steer number at each level of flight speed score difference.

\section{Management Implications}

Our hypothesis that steer weight gain on extensively managed semiarid rangeland would not be related to temperament was supported. No meaningful relationships were found between season-beginning or ending flight speed score and steer ADG. The stocking densities used here $(\sim 0.11-0.15 \mathrm{ha} / \mathrm{steer})$ are several orders of magnitude lower than in typical US feedlots ( 430-717 steers/ha). ${ }^{16}$ It was not surprising, then, that differences in effects of temperament on weight gain exist between extensively managed rangeland and feedlots. As a result, ranchers operating stocker enterprises with extensive management and low stocking densities on rangelands can potentially be less selective for temperament when assembling herds.

Previous studies have shown consistency and even increases in flight speed across measurements, ${ }^{4,8}$ and agitated cattle (particularly bulls) often remain agitated across handling events. ${ }^{5,17}$ However, many of our study steers had reduced flight speed scores at the end of the grazing season, which has also been observed by others. ${ }^{1,2}$ One possible explanation for reduced cattle temperament ratings over time is that cattle can become acclimated to handling and experience less stress if treated well across events. ${ }^{18-20}$ We can hypothesize that the flight speed score reductions observed here may have occurred because the steers were processed through the cattle handling facility once before with use of low-stress animal handling techniques (causing the animals to potentially habituate). ${ }^{1,2}$ However, because 5 months went by between flight speed scores in our study (making it difficult to determine if habitation did occur), another possible explanation is that ear tag application at the season-beginning weighing could have contributed to heightened agitation and therefore higher flight speed scores at the start of the grazing season. Regardless of the specific reason for the seasonal score reductions, again no meaningful relationships were found between flight speed score and steer ADG.

Prior studies have shown interesting variability in various temperament scores, so more research is needed to determine when and why temperament scores can be expected to differ over time. For example, larger animal size can be related to both increased ${ }^{4}$ and decreased ${ }^{7}$ temperament ratings, so there is still much to be learned about cattle temperament and its relationship to performance in a variety of settings.

\section{Where Do We go From Here?}

Given that low stocking densities were used in this study, it should be examined if temperament affects weight gains on semiarid rangeland at very high or ultra-high ("mob grazing") stocking densities (e.g., $\sim 200$ to $>1000$ steers/ha, respectively), ${ }^{21}$ which much more closely mimic stocking densities in feedlots. These much higher stocking densities (and associated increased human contact) may lead not only to potentially higher cattle stress, but may also affect weight gains via lower diet selectivity on rangeland. ${ }^{21}$ Under such circumstances, cattle temperament may still need to be a priority when assembling stocker steer herds.

Another open question is the transferability of the temperament improvements by our study steers to feedlots and subsequent feedlot performance. That is, will steers with higher initial flight speed scores maintain their lower scores and gain similar weight in feedlots compared with the initially calmer steers in their herd? It has been shown that flight speed of weaned calves was negatively related to later feedlot performance (high flight speed $=$ lower weight gains), ${ }^{2}$ so it is possible that extensively managed steers on semiarid rangeland may still perform relatively poorly in feedlots if they have poor temperaments. However, steers that habituate to handling on rangelands can also have reduced weight gains in feedlots compared to unhabituated counterparts. ${ }^{22}$ The relationship between rangeland temperament eventual feedlot weight gains should be examined in future studies, as it would benefit the cattle industry to understand if and how 
management and animal handling affects yearling steer performance on rangelands versus feedlots. As a start, our study shows that under extensive management and low stocking densities, steers with initially poor temperaments can be expected to still gain weight well, and may even be calmer at the end of the grazing season.

\section{Acknowledgments}

We thank members of the Crow Valley Livestock Cooperative, Inc., for providing livestock throughout the duration of this study. Low-stress livestock handling efforts by Mary Ashby, Jeff Thomas, Matt Mortenson, Tammy Kanode, Troy Smith, Todd Erickson, Tami Plechaty, Cody Jensen, and numerous student workers are much appreciated as well. Lauren Porensky, David Augustine, and anonymous reviewers are thanked for helpful comments on earlier versions of this manuscript. Funding was provided by the USDA-ARS.

\section{References}

1. King, D.A., C.E. Schuehle Pheiffer, R.D. Randel, T.H. Welsh, R.A. Oliphint, B.E. Baird, K.O. Curley, R.C. Vann, D.S. Hale, and J.W. Savell. 2006. Influence of animal temperament and stress responsiveness on the carcass quality and beef tenderness of feedlot cattle. Meat Science 74:546-556.

2. Behrends, S.M., R.K. Miller, F.M. Rouguette, R.D. Randel, B.G. Warkington, T.D.A. Forbes, T.H. Welsh, H. LipPKe, J.M. Behrends, G.E. Castens, and J.W. Holloway. 2009. Relationship of temperament, growth, carcass characteristics, and tenderness in beef steers. Meat Science 81:433-438.

3. Voisinet, B.D., T. Grandin, J.D. TAtum, S.F. O'Connor, And J.J. STRuthers. 1997. Feedlot cattle with calm temperaments have higher average daily gains than cattle with excitable temperaments. Journal of Animal Science 75:892-896.

4. Muller, R., And M.A.G. von Keyserlingk. 2006. Consistence of flight speed and its correlation to productivity and to personality in Bos taurus beef cattle. Applied Animal Behaviour Science 99:193-204.

5. Grandin, T. 1993. Behavioral agitation during handling of cattle is persistent over time. Applied Animal Behaviour Science 36:1-9.

6. Northcutt, S., And B. Bowman. 2010. By the numbers: docility genetic evaluation research. ANGUS Journal 2010:A1.

7. Fordyce, G., R.M. Dodt, And J.R. Wythes. 1988. Cattle temperaments in extensive beef herds in northern Queensland 1. Factors affecting temperament. Australian Journal of Experimental Agriculture 28:683-687.

8. Hoppe, S., H.R. Brandt, S. Konig, G. Erhardt, and M. GaUly. 2010. Temperament traits of beef calves measured under field conditions and their relationships to performance. Journal of Animal Science 88:1982-1989.

9. Morris, C.A., N.G. Cullen, R. Kilgour, and K.J. Bremner. 1994. Some genetic factors affecting temperament in Bos taurus cattle. New Zealand Journal of Agricultural Research 37:167-175.

10. Burrow, H.M., G.W. Seifert, and N.J. Corbet. 1988. A new technique for measuring temperament in cattle. Proceedings of the Australian Society of Animal Production 17:154-157.

11. Baszczak, J.A., T. Grandin, S.L. Gruber, T.E. Engle, W.J. Platter, S.B. Laudert, A.L. Shroeder, and J.D. Tatum. 2006. Effects of ractopamine supplementation on behavior of British, Continental, and Brahman crossbred steers during routing handling. Journal of Animal Science 84:3410-3414.
12. Vetters, M.D.D., T.E. Engle, J.K. Ahola, and T. Grandin. 2013. Comparison of flight speed and exit score as measurements of temperament in beef cattle. Journal of Animal Science 91:374381.

13. GRAndin, T. 1990. Design of loading facilities and holding pens. Applied Animal Behaviour Science 28:187-201.

14. Grandin, T. 1997. The design and construction of facilities for handling cattle. Livestock Production Science 49:103-119.

15. Grandin, T. 1998. Review: Reducing handling stress improves both productivity and welfare. Professional Animal Scientist 14:1-10.

16. National Cattlemen's Beef Association, 2006. Fact sheet: Feedlot finishing cattle. Available at: http://www.beefusa.org/uDocs/Feedlot $\%$ 20finishing\%20fact $\% 20$ sheet $\% 20$ FINAL_4\%2026\%2006.pdf. Accessed 3 February, 2015.

17. Curley, K.O., J.C. Paschal, T.H. Welsh, and R.D. Randel. 2006. Technical note: Exit velocity as a measure of cattle temperament is repeatable and associated with serum concentration of cortisol in Brahman bulls. Journal of Animal Science 84:3100-3103.

18. Crookshank, H.R., M.H. Elissalde, R.G. White, D.C. Clanton, and H.E. Smalley. 1979. Effect of transporting and handling of calves upon blood serum composition. Journal of Animal Science 43:430-435.

19. Krohn, C.C., J.G. Jago, and X. Boivin. 2001. The effect of early handling on the socialization of young calves to humans. Applied Animal Behaviour Science 74:121-133.

20. Cooke, R.F., D.W. Bohnert, B.I. Cappellozza, C.J. Mueller, And T. Delcurto. 2012. Effect of temperament and acclimation to handling on reproductive performance of Bos taurus beef females. Journal of Animal Science 90:3547-3555.

21. Peterson, D., M. Brownlee, and T. Kelley. 2013. Stocking density affects diet selection. Rangelands 35:32-66.

22. Francisco, C.L., R.F. Cooke, R.S. Mareues, R.R. Mills, and D.W. BohnerT. 2012. Effects of temperament and acclimation to handling on feedlot performance of Bos taurus feeder cattle originated from a rangeland-based cow-calf system. Journal of Animal Science 90:5067-5077.

Authors are Research Ecologist (Reeves, Justin.Reeves@ars.usda.gov), and Research Leader (Derner), US Dept of Agriculture-Agricultural Research Service-Rangeland Resources Research Unit, Cheyenne, WY 82009, USA. Any use of trade, firm, or product names is for descriptive purposes only and does not imply endorsement by the U.S. Government. The U.S. Department of Agriculture (USDA) probibits discrimination in all its programs and activities on the basis of race, color, national origin, age, disability, and where applicable, sex, marital status, family status, parental status, religion, sexual orientation, genetic information, political beliefs, reprisal, or because all or part of an individual's income is derived from any public assistance program. (Not all probibited bases apply to all programs.) Persons with disabilities who require alternative means for communication of program information (Braille, large print, audiotape, etc.) should contact USDA's TARGET Center at (202) 720-2600 (voice and TDD). To file a complaint of discrimination, write to UDSA, Director, Office of Civil Rights, 1400 Independence Avenue, S.W., Washington, D.C. 20250-9414, or call (800) 7953272 (voice) or (202) 720-6382 (TDD). USDA is an equal opportunity provider and employer. 